\author{
Military Technical College \\ Kobry El-Kobbah, \\ Cairo, Egypt.
}

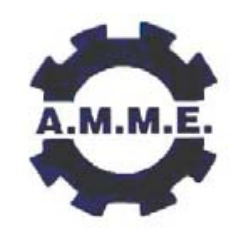

$13^{\text {th }}$ International Conference on Applied Mechanics and Mechanical Engineering.

\title{
PRODUCTION OF BIMETALLIC AND TRIMETALLIC MATERIALS BY EXPLOSION WELDING AND ALLIED PROCESSES
}

\author{
TURŇA* M., NESVADBA** P., ROLC ${ }^{* * *}$ S., ČAPLOVIČ* L'., TURŇOVÁ* Z.
}

\begin{abstract}
The paper and talk deal with the research results in the field of welding the combined metals such as Ti-Cu, Ti-Al, Sn-Cu, Al-Mg alloy, Monel-steel, Pb-steel, AISi alloy-Cu, Ta-Monel, Ta-Stainless Steel, Monel-Ta, steel-Ti-Al, steel-Cu-Al, etc., as well as the processes allied. The combinations that are not mentioned in the paper will be presented during the talk.

The results were attained in collaboration with the Research Institute of Industrial Chemistry, Pardubice-Semtin (Czech Republic) and the Slovak University of Technology, Department of Welding, Faculty of Materials Science and Technology, Trnava (Slovak Republic). The bimetals and trimetals were produced using the Semtex S explosive. The quality of joints was evaluated by ultrasonic detection, optical microscopy, microhardness measurements and X-ray microanalysis.
\end{abstract}

\section{KEY WORDS}

Explosion Welding, Explosive, Welding Metals, Welding Parameters, Bimetal, Trimetal, Quality Control.

* Faculty of Materials Science and Technology, Slovak University of Technology

Bratislava, Trnava, Slovak Republic 


\section{INTRODUCTION}

Regarding its productivity, the explosion welding is not the technology that could compete with such technologies as GMAW, resistance welding, laser welding, etc. In spite of that, it has an irreplaceable position in fabrication of special materials. Figs. 1a and $1 \mathrm{~b}$ show the worldwide trends in the field of research and development of special materials and technologies, where the materials produced by explosion are given within multi-materials and the explosion welding belongs to the group named Other Welding Processes within individual welding technologies [1].

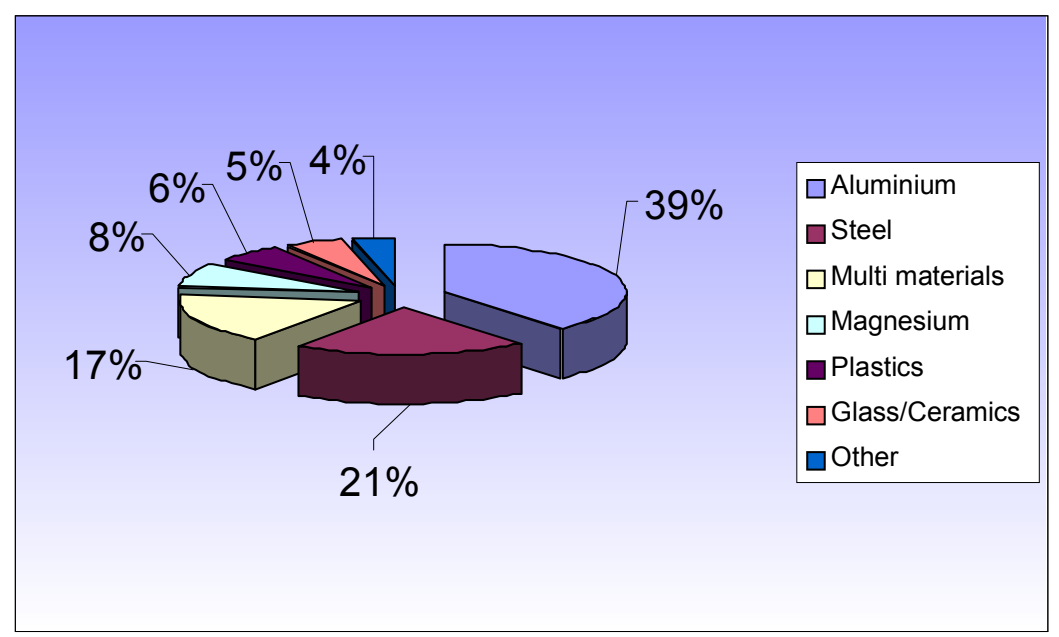

Fig. 1a. Fields of Research / Materials [1].

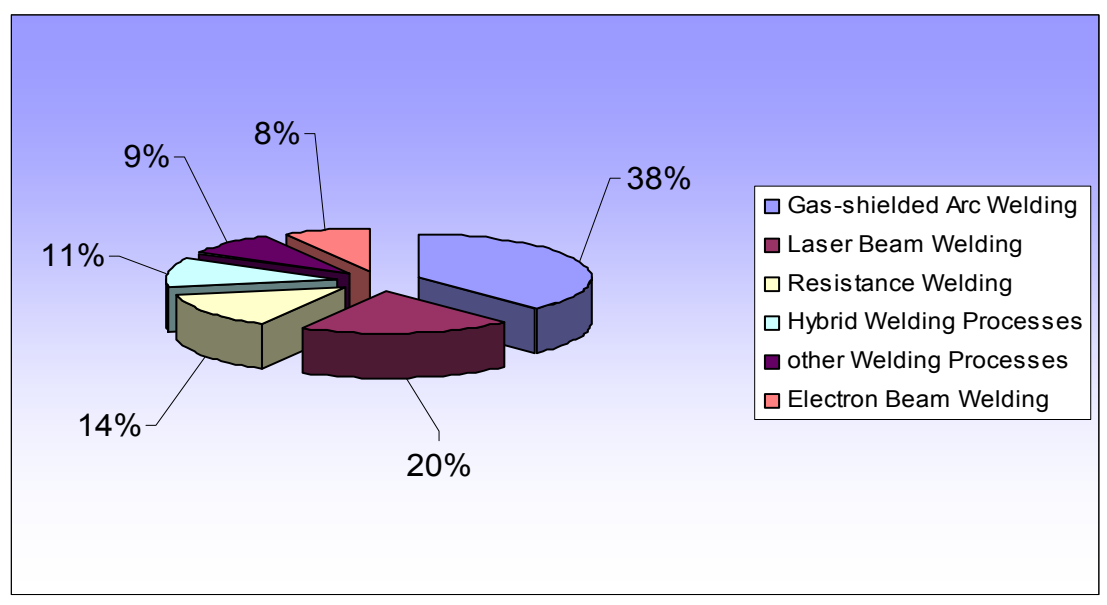

Fig. 1b. Fields of Research / Welding [1].

In former Czechoslovakia, explosion welding had a rich history, mainly owing to merits of the Research Institute of Industrial Chemistry in Pardubice - Semtin, which successfully co-operated, besides many others, with the Faculty of Mechanical Engineering (Department of Physical Metallurgy, Welding and Founding) of the Slovak Technical University in Bratislava and later also Explosia Inc., RIICH Pardubice with the Welding Department, and the Faculty of Materials Science and Technology of the Slovak University of Technology in Trnava. This co-operation resulted in several research tasks, which were implemented into technical practice, such as: 
- Al-steel bimetals for electrolyzer for manufacture of aluminum and building a workplace for explosion welding (ZSNP Žiar nad Hronom, SR), including the mass surfacing of 16 bimetals on one firing, Ta-Cu targets for sputtering in micro electronics (TESLA Lanškroun, CR), wear-resistant splice plates made of Hadfield steel - cast steel for Wagon Works (Vagónka Poprad, SR),

- bimetallic Cu-AISi clamps for high voltage and very high voltage electricity lines (Elektrovod Kremnica, SR),

- bimetallic contact screws for cars (PAL Kroměříš, $C R$ ), including mass surfacing (500 pieces on one firing),

- Pb-steel bimetals for the Chemical Works (former "Dynamit" plant, SR),

- grey cast iron - structural carbon steel bimetals etc.

- Cu-Al 99.9999 bimetals (M.R.C. New York) and others.

Bonding of such bimetals as Ti-Cu, Ti-Al, Sn-Cu, Al-Mg alloy, Cu-Mg alloy, Monelstainless steel, Monel-Ta, and also trimetals such as steel-Cu-Al and steel-Ti-Al was also solved. Many experiments in the field of splitting, strengthening metals etc. were performed at RIICH, Explosia Plant in Pardubice, CR.

\section{EXPLOSION WELDING}

The well-known Semtex explosives are used within the Czech and Slovak Republics for technological processing of metals. In the past, Semtex S 25 explosive was mostly used for welding. At present, Semtex S 30 and also other explosives adapted to physical and mechanical properties of welded materials are being used. The characteristics of selected Semtex type explosives are given in Table 1.

Table 1. Explosives for hardening and cladding (15).

\begin{tabular}{|c|c|c|c|}
\hline Parameters & Unit & SEMTEX $^{(\circledast)}$ S 30 & SEMTEX $^{\circledR} 10-\mathrm{SE}$ \\
\hline Type & & Powder & Plastic \\
\hline Explosion heat & $\mathbf{k J} / \mathbf{k g}$ & 1,277 & 3,992 \\
\hline Swath volume & $\mathrm{dm}^{3} / \mathrm{kg}$ & 420 & 944 \\
\hline Oxygen balance & $\% \mathrm{O}_{2}$ & -3 & -62.6 \\
\hline Detonation velocity & $\mathrm{m} / \mathrm{s}$ & 2,200 & 7,000 \\
\hline Trauzl test & ml & -- & -- \\
\hline Brisance by Hess & $\mathbf{m m}$ & 10 & 20 \\
\hline RWS (blasting gelatine) & $\%$ & 12 & 72 \\
\hline Temperature of explosion & ${ }^{\circ} \mathrm{C}$ & 1,023 & 2,600 \\
\hline Transmission of detonation & $\mathbf{c m}$ & -- & -- \\
\hline Density & $\mathrm{kg} / \mathrm{m}^{3}$ & -- & 1,450 \\
\hline Water resistance & - & no & excellent \\
\hline Smallest diameter permitted & $\mathbf{m m}$ & -- & 1.5 \\
\hline Loose mass & G.mm $\mathrm{m}^{-3}$ & 1.1 & -- \\
\hline
\end{tabular}


Approximate dependence of detonation velocities of Semtex $S$ explosives on their thickness is given in Fig. 2.

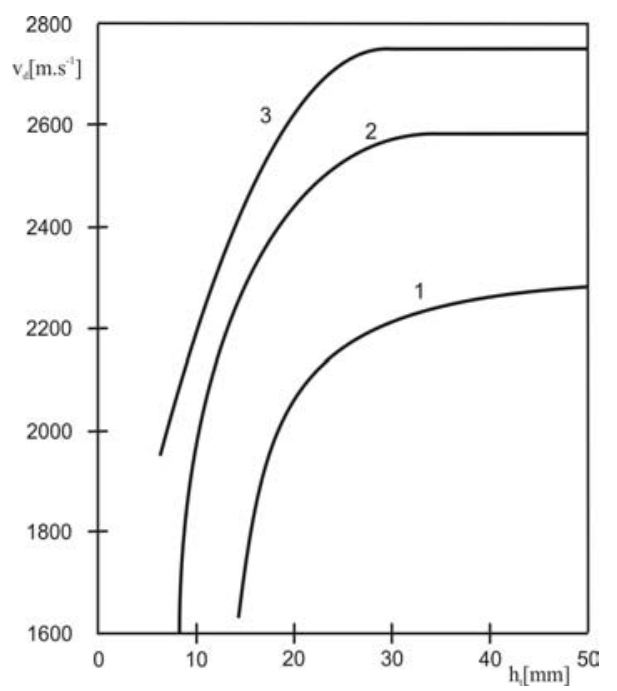

Fig. 2. Dependence of detonation velocity $v_{d}$ on explosive thickness $h(9)$.

(1-Semtex $S 25$ at $\varsigma_{t}=1.20 \mathrm{~g} . \mathrm{cm}^{-3}, 2$ - Semtex $S 30$ at $\varsigma_{t}=1.15 \mathrm{~g} . \mathrm{cm}^{-3}, 3-$ Semtex $S 35$ at $\varsigma_{t}=1.10 \mathrm{~g} \cdot \mathrm{cm}^{-3}$ )

In most cases, parallel arrangement of welded materials (welding assembly) was applied, as shown in Figs. 3a, 3b.

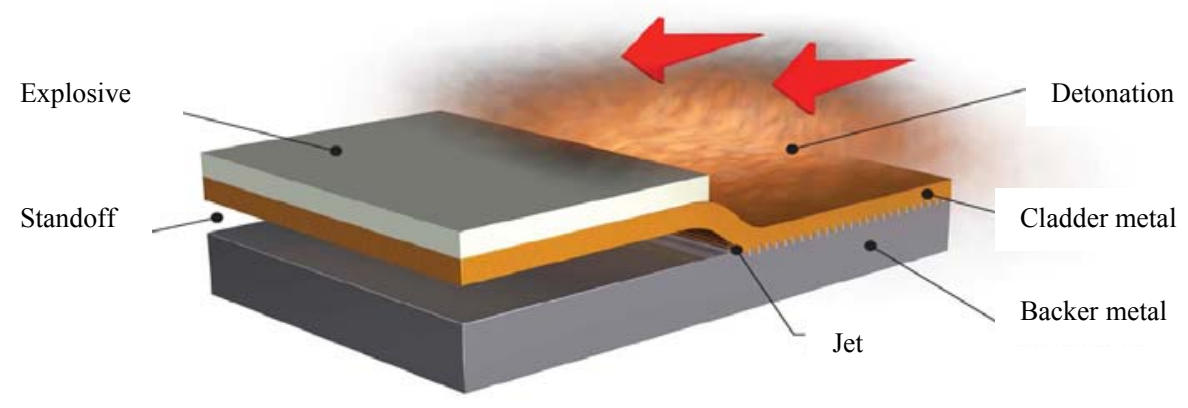

Fig. 3a. Principal scheme of explosion welding (9).

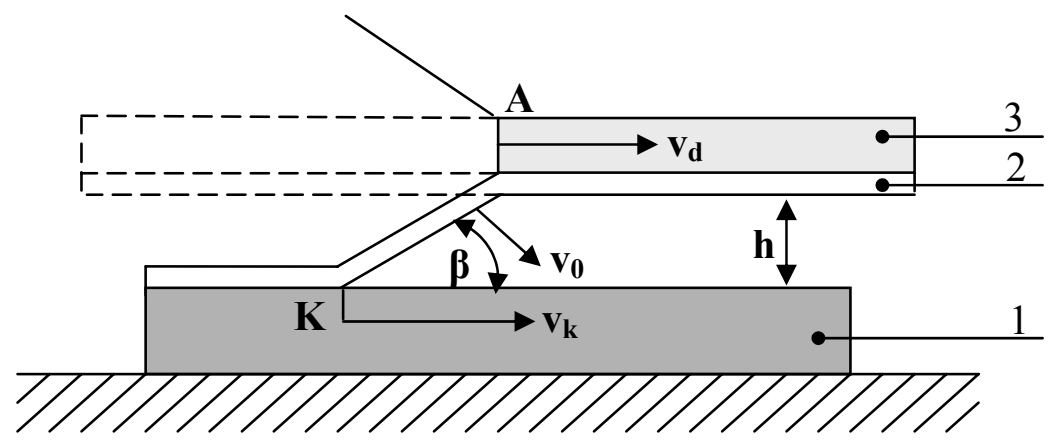

Fig. 3b. Kinematic scheme of explosion welding $(3,9)$.

As known, the main welding parameters are $v_{d}, v_{o} v_{k}, h, \beta$. From Fig. $3 b$, the basic relationships for Semtex S 25 explosive (which is now preferentially used at RIICH 
Explosia Inc. Pardubice) can be derived. By the authors Chládek, L. and Vacek, J., the following $v_{d}$ and $\delta$ parameters were suggested:

$$
\mathrm{V}_{\mathrm{d}}=\left(3256-\frac{114110}{h_{t}^{2}}\right) \cdot\left(\varsigma_{\mathrm{t}}-0,325\right) \quad\left[\mathrm{m} \cdot \mathrm{s}^{-1} ; \mathrm{mm}, \mathrm{g} \cdot \mathrm{cm}^{-3}\right]
$$

for $10 \leq h_{t} \leq 35$; if $h_{t}>35 \mathrm{~mm}, h_{t}=35 \mathrm{~mm}-$ (upper limit layer);

$$
\delta=\frac{0,4007-0,004725 h_{t}}{0,3485+\frac{1}{\omega}},
$$

where $h_{t}$ is the explosive thickness, $\rho_{t}$ - explosive density, $\omega$ - weight proportion of the charge to accelerated material.

For better apprehension, let us state that the detonation velocities of explosives suitable for explosion welding usually vary within the range from 900 to $3500 \mathrm{~m}^{-1} \mathrm{~s}^{-1}$. The impact velocity of material accelerated by explosive usually attains 300 to $1500 \mathrm{~m} . \mathrm{s}^{-1}$ on the path formed by distance spacing. The necessary spacing between the plates and/or opening and the outer wall of expanded tube varies within several tenth of $\mathrm{mm}$ up to several $\mathrm{mm}$. The entire event takes place within the time in order of tens to hundreds microseconds ( $\mu \mathrm{s})$. Weldability of various materials is given in Table 2.

Manufacturing of composite and multilayer sheet billets of heterogeneous metal and alloys of up to $12 \mathrm{sq}$. $\mathrm{m}$. area, front 0.5 to $700 \mathrm{~mm}$ thickness can be carried out directly by welding as well by combination of welding and rolling. The most promising joints can be obtained by joining the following pairs of metals: titanium alloys + steel, aluminum alloys + steel, zirconium alloys + steel, magnesium alloys + steel, nickel alloys + steel, copper alloys + steel, aluminum alloys + titanium (alloys), aluminum alloys + magnesium, aluminum alloys + copper, lead + steel, lead + copper, niobium + zirconium alloys and others (16).

\section{MATERIALS FOR REPARATION OF MULTILAYER ARMOURS}

Multilayer metal structure is mostly prepared as a three-layer material. Armour steel is the base of multilayer material. Top-layer is the material the high hardness of which can be achieved while preserving certain degree of toughness. The interlayer is the material which enables armour and tool steel to be joined, furthermore, it enables heat processing, it works as a diffusion barrier, balances different dilatation of the materials used for the base and top layers, prevents from propagation of cracks, ensure integrity of the armour on repeated ballistic loading and, in an ideal case, it contributes to increased ballistic resistance.

For the base armour layer (backer metal), it was possible to use commercially available armour steel. Cladder metal for the top layer of the multilayer armour was tool steel. Nickel alloys were the material used for interlayer. Fig. 4 shows the structure of the weld interface. 
Table 2. Weldability of materials in explosion welding (14).

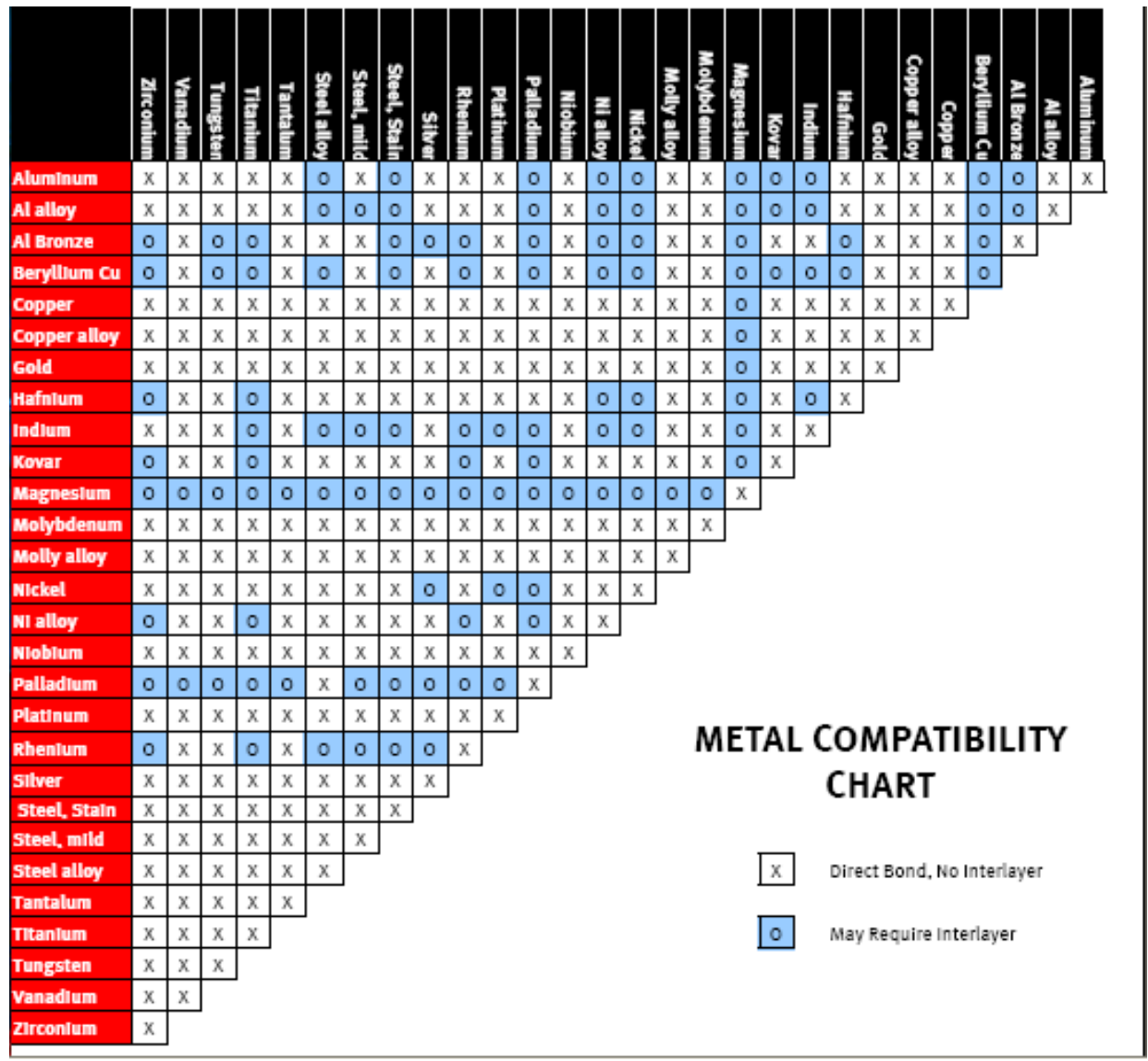

Functional samples were prepared by means of explosion welding technology (EWT). In terms of this technology, it is necessary that the materials chosen are available in the form of sheets and plates with properties suitable for cladding (suitable hardness and quality of surface, ductility etc.). The availability of tool steels in the form of sheets is a little worse; some types of tool steels in the form of sheets are commercially unavailable. In such case, it is not possible to use EWT for preparation of functional samples. The tool steel can be prepared in the form of sheet but at relatively high costs, and then EWT becomes rather ineffective.

Selection of materials is influenced by the fact, that multilayer structure is heat processed as the whole. By heat processing, the quality shall be achieved both of base armour layer (high hardness and toughness) and top layer (above all hardness). At the same time, the process must not lead to the degradation of the material (materials) of interlayer. Usually, the decisive factor is quality heat processing of the top layer, detrimental, however, to the quality of the base armour layer (lower strength and hardness).

\section{THE TESTING OF MATERIALS}

The most important part in the development of the materials suitable for ballistic protection is the testing of their ballistic resistance by firing tests, or, potentially, the 


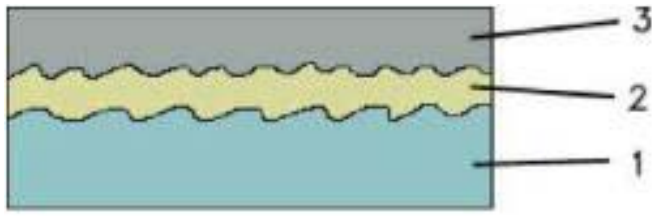

1. Base armour layer

2. Interlayer or several inter-layers

3. Front plate - top lay

Fig. 4. Explosive welding: three-layer structure.

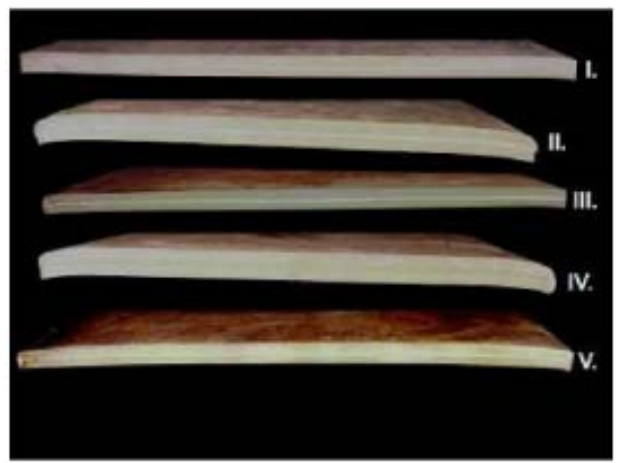

testing of their resistance to impact of fragments or effects of mines explosion etc. Figure 5 shows the cross section of the plates after projectile penetration. In addition to the projectile penetration, separation of individual layers of the armour, cracks propagation, spalls formation etc. is also observed and Fig. 6 the monitoring of scratches.
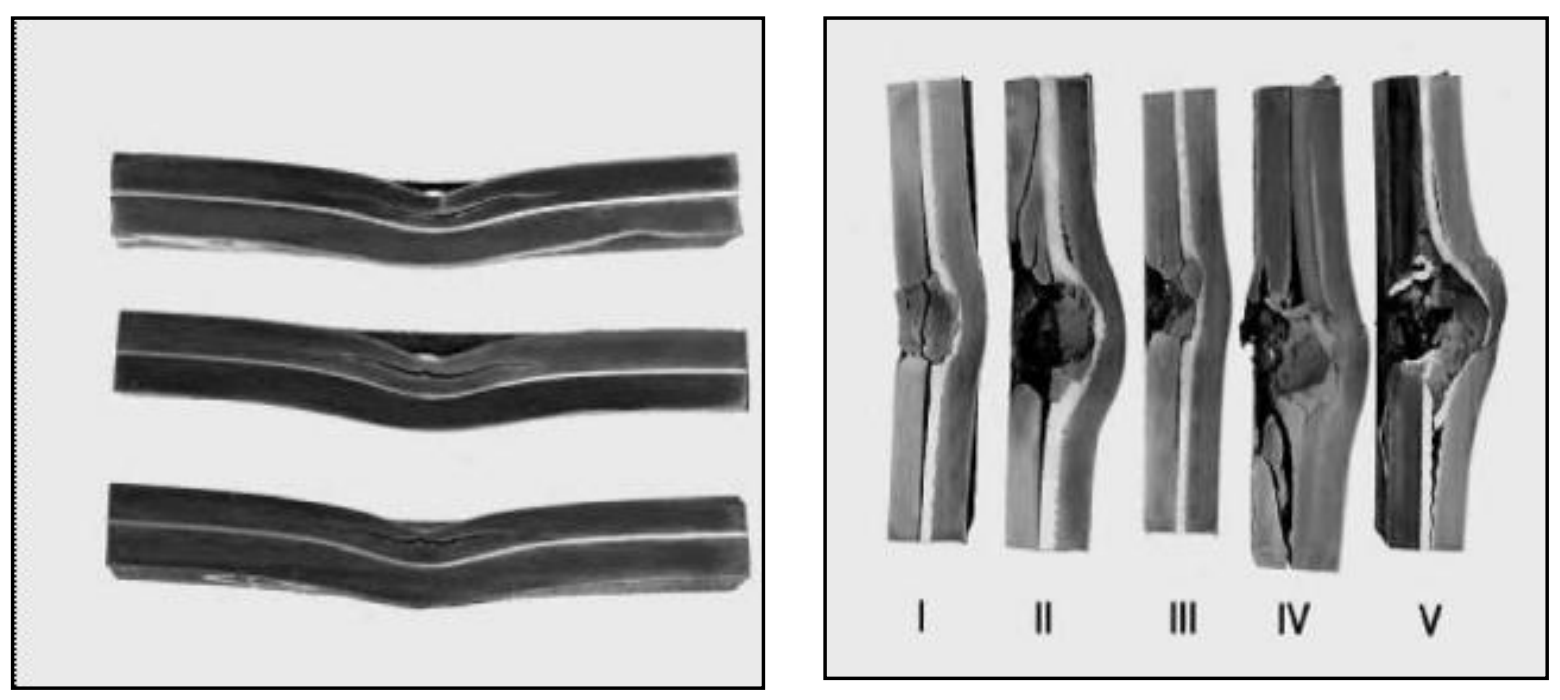

Fig. 5. Cross section of plates after projectile penetration.

\section{NUMERICAL SIMULATION OF EXPLOSIVE WELDING}

Numerical simulations (Fig. 7) are the part of the development. The objective is to utilize the simulation to model the actions and optimize the incoming parameters. It is possible to measure tensile stresses, pressures, plastic deformations, velocities, and the possibilities can be evaluated of rise of rupture in the form of spall.

\section{FINAL MANUFACTURING}

After verification of needed properties of multilayer structure and definition of suitable materials combination, it is possible to start with manufacturing the multilayer material 


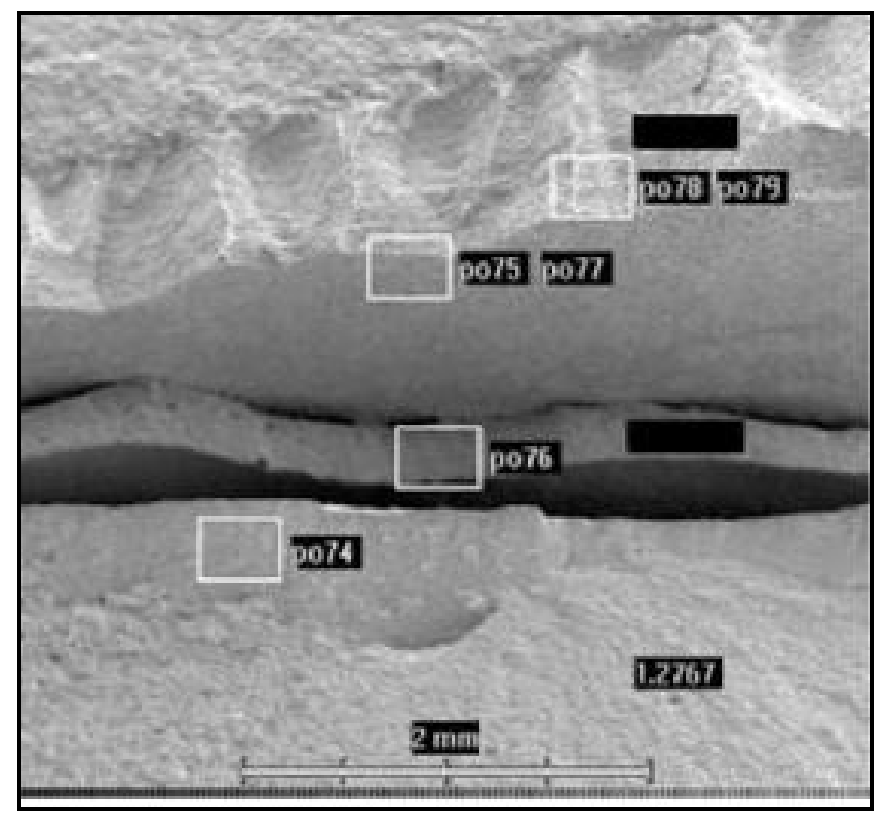

Fig. 6 The monitoring of scratches.

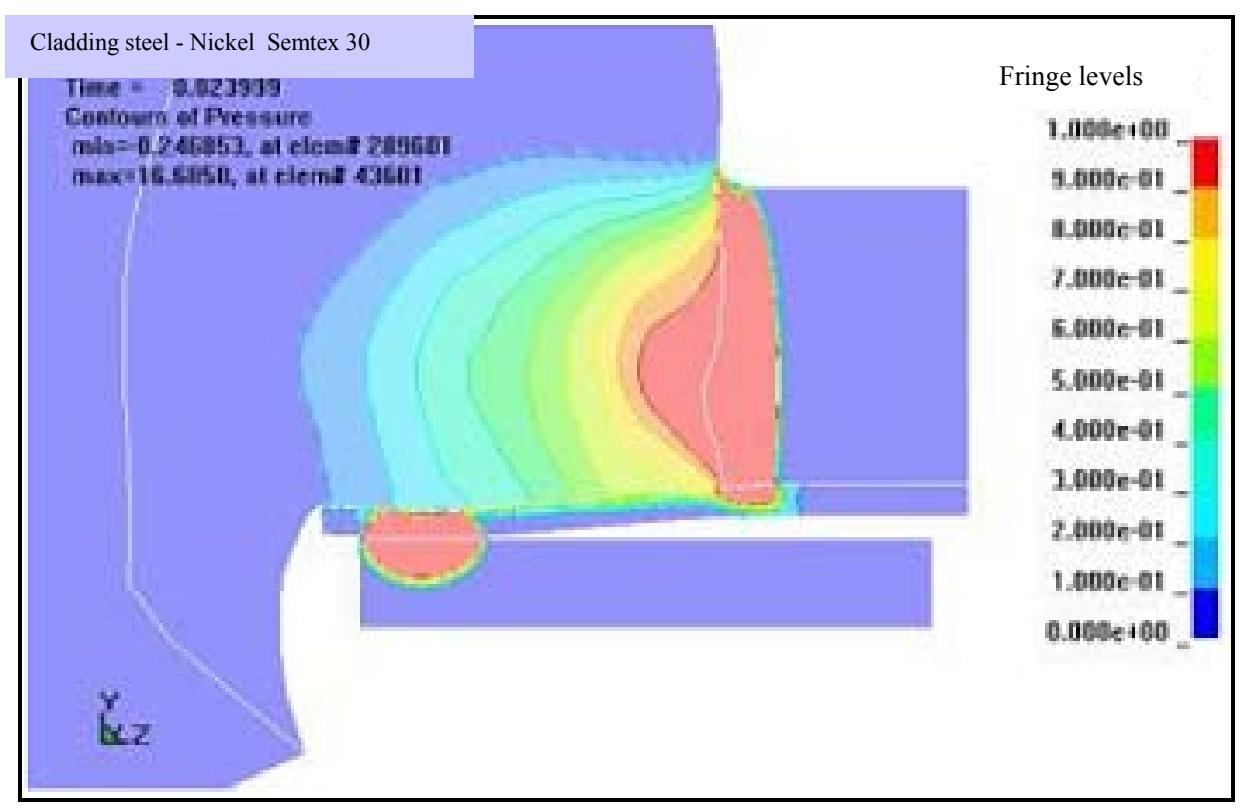

Fig. 7 Numerical simulation of explosive welding.

by means of Roll Technology. Selected combinations of metallic materials is processed by Roll Technology only, or it is possible to utilize EWT for preparation of semi-finished products for subsequent rolling-down. The semi-finished products are usually prepared in the form of bimetallic plates - tool steel and armour steel cladded with suitable interlayer. These plates are subsequently rolled together. The advantage of semifinished product prepared in this way is the quality weld interface of the bimetal, which facilitates its further processing in roll stand. The semi-finished products for rolling-down can be prepared in almost any size. Dimensions from 2 to $4 \mathrm{~m}^{2}$ are common. 
Preparation of model multilayer materials by means of explosive welding technology has found its application and serves primarily for a quick testing of some functional properties of the proposed multilayer structure. Various material combinations can be joined in various thickness ratios, but with limitation to the starting materials processed to the form of sheets and plates. Manufacturing of model structures using EWT is relatively quick and not very costly. This enables, within a short time, to prepare multilayer materials in the most various material combinations. After testing of properties and selection of suitable material combination it is possible to start with further production by the follow up technology, in this case roll forming. The scope of material combinations is very wide.

\section{QUALITY CONTROL OF BIMETALLIC AND TRIMETALLIC METALS}

Recently, the research in the field of welding the combined metals was carried out. Bellow are some results of checking the joints quality by optical microscopy and X-ray microanalysis. The results are presented in Figs. $8-16$.

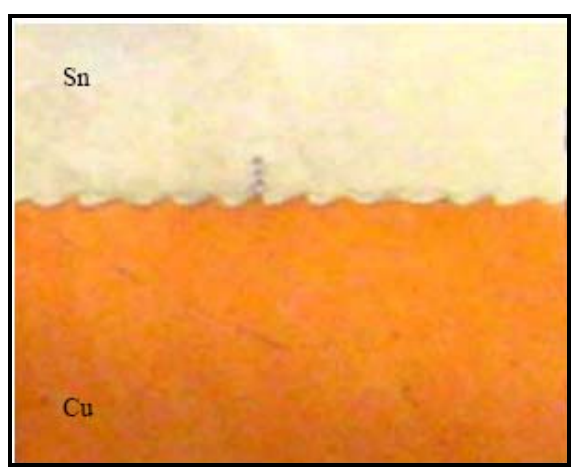

Fig. 8 Macrostructure Cu-Sn.
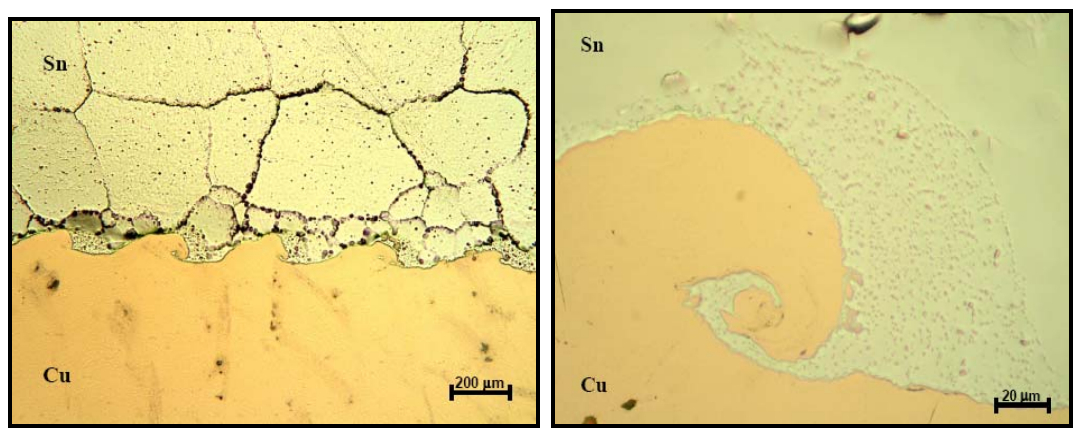

Fig. 9 Microstructures of $\mathrm{Cu}-\mathrm{Sn}$ interface (Explosive Semtex So12K), $\mathrm{v}_{\mathrm{d}}=1150 \mathrm{~m} / \mathrm{s}$. 


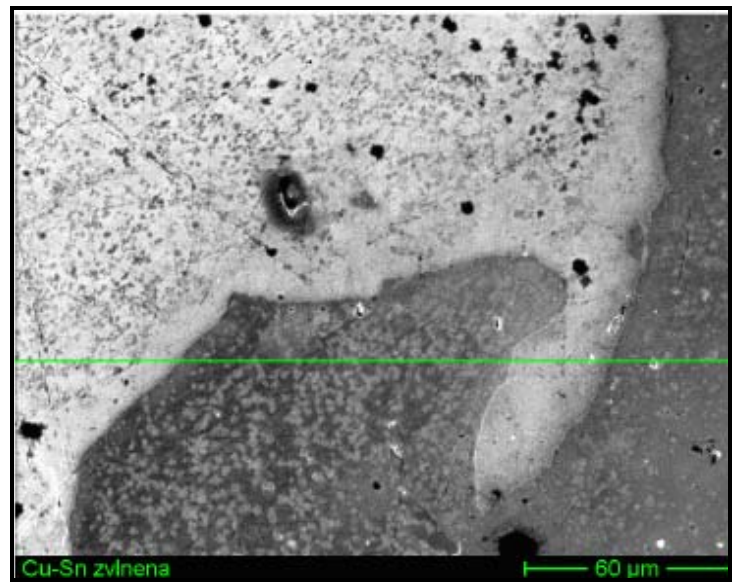

Fig. 10. The course of change in $\mathrm{Cu}$ and $\mathrm{Sn}$ concentration through the bimetal interface.

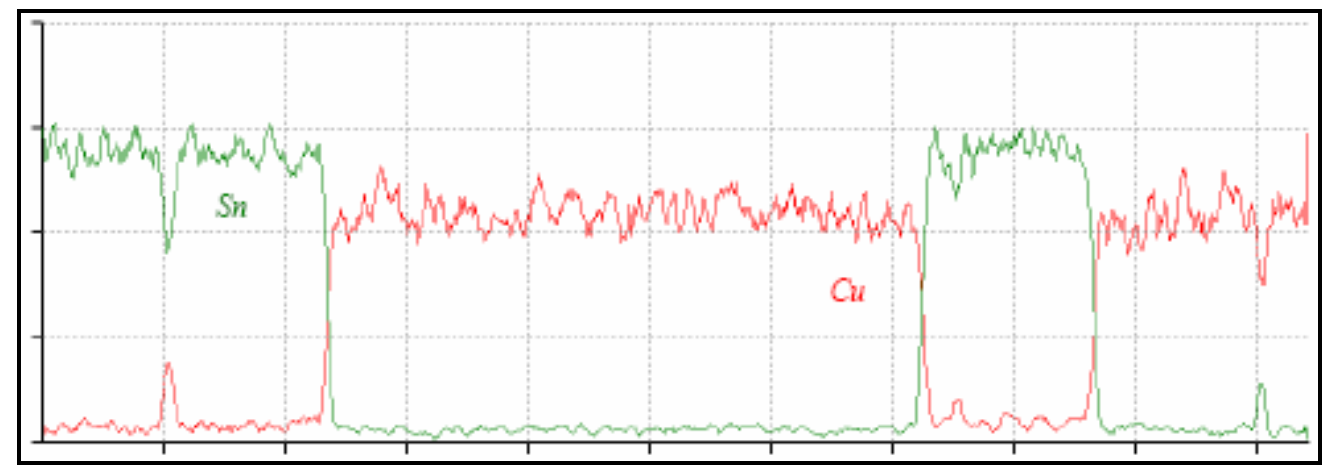

Fig. 11. Cu and Sn line profiles across the weld interface.

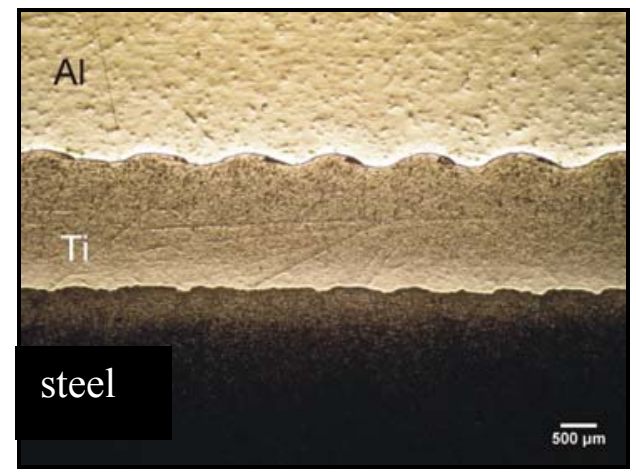

Fig. 12. Macrostructure of trimetal (section perpendicularly to the $\mathrm{Ti}-$ steel explosion direction and in the Al - Ti explosion direction). 


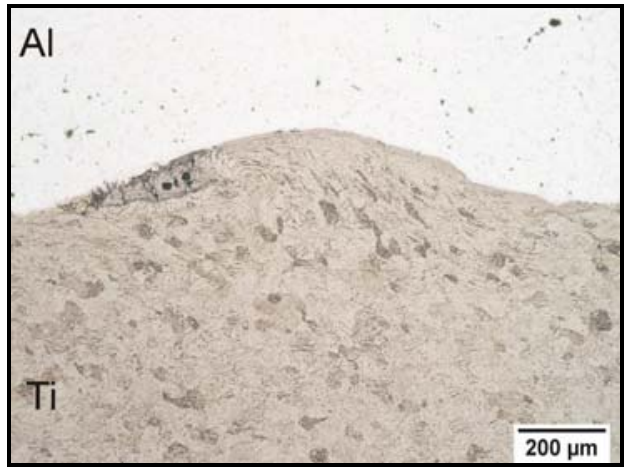

Fig. 13. Microstructure of $\mathrm{Ti}-\mathrm{Al}$ interface (Keller etching).

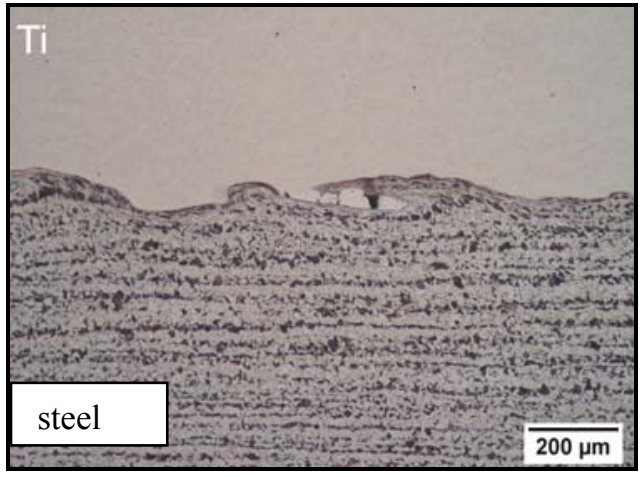

Fig. 14. Microstructure of $\mathrm{Ti}-$ steel interface.

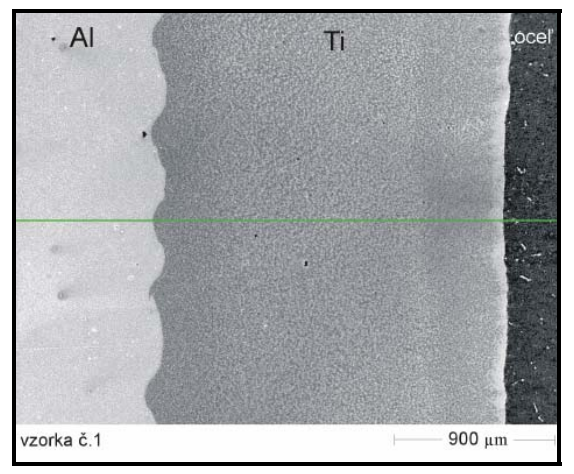

Fig. 15 Measurement area through trimetal $\mathrm{Al}-\mathrm{Ti}$ - steel interface (steel: $\mathrm{h}=39 \mathrm{~mm}, \mathrm{Ti}: \mathrm{h}=2 \mathrm{~mm}, \mathrm{Al}: \mathrm{h}=16 \mathrm{~mm}$, detonation Ti to steel $11523, \mathrm{v}_{\mathrm{d}}=2190 \mathrm{~m} / \mathrm{s}$, detonation Al to Ti, $v_{d}=2705 \mathrm{~m} / \mathrm{s}$, Semtex S 30)

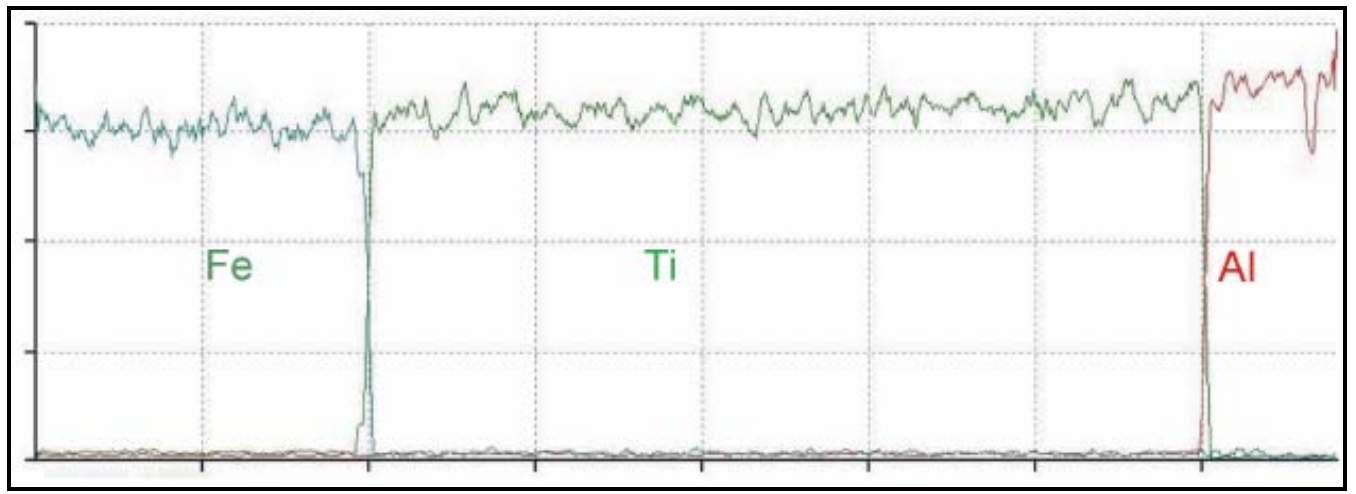

Fig. 16 Course of the change in $\mathrm{Al}, \mathrm{Ti}$ and Fe concentration through the trimetal interface

\section{CONCLUSIONS}

The lecture presents just a part of knowledge from the technological processing of metals by explosion. The most significant results have been implemented into technical practice, a part of results was patented and a part was published. These results will be mentioned in the lecture. 
The most recent works were performed in cooperation with RIICH Explosia Pardubice $(\mathrm{CR})$ and are given in the references. The faculty bachelors, graduates working on their thesis and the doctorate graduants were involved in these works.

The specialists of V RIICH Pardubice have a long-year experience in the work with explosives and with technological processing of materials by explosion.

The workplaces of the Faculty of Materials Science and Technology of SUT Trnava and FCHFT SUT Bratislava have available suitable instrumentation, where quality of joints can be assessed by the techniques of optical microscopy, electron microscopy and Xray microanalysis, applied to their boundary zone (in case of bimetals, trimetals etc.). There are efforts to contribute also to elucidation of mechanism of joint formation in explosion welding and also to enhance the structural stability of the joint boundary.

Special attention will be in the future devoted to formation and growth of intermetallic phases in the boundary zone of combined metals. A suitable software for this purpose is available at the Faculty. Besides the others efforts we also try to oppose the statement of big companies supposing that the small companies dealing with technological processing of materials by explosion have no chance to survive.

This contribution was elaborated within 1/3191/06 project supported by VEGA (Science and Education Grant Agency) of Ministry of Education and Academy of Science, Slovak Republic

\section{REFERENCES}

[1] Middelforf, K., Herold, H., von Hofe, D.: Trends in Joining - Value Added by Welding. Proceed. of the IIW Int. Confer. on Benefits of New Methods and Trends in Welding to Economy, Productivity and Quality. 10-15, July, Prague, (2005).

[2] Chladek, L. and Nemecek, J. and Vacek. J.: Explosion welding of metals and allied processes. Prague, (1979).

[3] Turna, M.: Special Welding Methods. Alfa. Bratislava, pp. 368, (1979).

[4] Kovacic, I.: Design of fabrication technology for large-area $\mathrm{Cu}$-Ti bimetals. Thesis. Faculty of Materials and Technology STU Trnava, pp. 69, (2005).

[5] Solava, J.: Design of explosion welding technology for combined metals. Thesis. Faculty of Materials and Technology STU Trnava, pp. 79, (2006).

[6] Demianova, K.: Design of welding technology for joining Mg alloy with Al. Thesis. Faculty of Materials and Technology STU Trnava, pp. 70, (2007).

[7] Benak, M.: Explosion welding of bimetalic tubeplate. Thesis. Faculty of Materials and Technology STU Trnava, pp. 95, (2007).

[8] Belokostolsky, T.: Design of welding technology for joining Mg alloy with selected metals. Thesis. Faculty of Materials and Technology STU, Trnava, pp. 75, (2007).

[9] Gottstein, M.: Design of fabrication technolgy for trimetal Al - $\mathrm{Cu}$ - structural carbon steel. Thesis. Faculty of Materials and Technology STU, Trnava, pp. 80, (2007)

[10] Bulik, M.: Design of fabrication technology for trimetal steel - Ti - Al. Thesis. Faculty of Materials and Technology STU Trnava, pp. 65, (2008). 
[11] Turna, M. and Nesvadba, P. and Turnova, Z.: Explosion Welding. Welder. (in print), (2008).

[12] Turna, M. et al.: Progresive metallurgical joining (and allied processes) of special and combined materials by ecologically friendly technologies and consumables. Project of Scientific Grant Agency (VEGA) of the Ministry of Education and the Slovak Academy of Sciences. (2006 - 2008).

[13] Nesvadba, P.: Explosion welding and allied processes. Lecture. Faculty of Materials and Technology STU Trnava, (2007).

[14] Turna, M.: Special methods of solid state welding of metals. Lectures presented at IWE. Engineering Faculty at the Czech Technical University Prague, (2007).

[16] Turna, M.: Special methods of solid state welding of metals. Lectures presented at IWE. The Welding Research Institute Bratislava, (2007).

[17] http://www.pacaero.com/pdf/resourcecenter/Insert\%2020Bonded\%20 Metal\%20C ombinations.0906.v1.pdf

[18] www.explosia.cz

[19] http://welding.vstu.ru/ 